International Journal of Child, Youth and Family Studies (2016) 7(2): 307-323

DOI: $10.18357 /$ ijcyfs 72201615723

\title{
RE-CREATING SOCIAL FUTURES: THE ROLE OF THE MORAL IMAGINATION IN STUDENT-TEACHER RELATIONSHIPS IN ALTERNATIVE EDUCATION
}

\section{Jennifer A. Vadeboncoeur and Renira E. Vellos}

\begin{abstract}
In this article, we describe a quality of student-teacher relationships that supports re-engagement in alternative education. This quality is based upon the principle of accept and build: a dialectical principle that simultaneously includes both student and teacher accepting what the other offers in the present moment while building new social futures in relation. We argue that this form of relation is both a means and an outcome of moral imagining. The article is in three sections. We begin by providing a brief review of the literature on student-teacher relationships. Then, drawing together the literature on moral imagination, we describe and exemplify the principle of accept and build with research from Australia and Canada. From this perspective, student-teacher relationships can be positioned as developing projects of the moral imagination with implications for the recreation of social futures. Although the label of "second chance" is often applied pejoratively to alternative and flexible programs, we argue that this should be viewed as a strength rather than a weakness.
\end{abstract}

Keywords: student-teacher relationships, alternative education, moral imagination, social futures, Vygotsky

Jennifer A. Vadeboncoeur (corresponding author) is Associate Professor of Human Development, Learning, and Culture at The University of British Columbia, 2125 Main Mall, Vancouver, BC V6T 1Z4. Email: j.vadeboncoeur@ubc.ca

Renira E. Vellos is a doctoral candidate in Human Development, Learning, and Culture at The University of British Columbia, 2125 Main Mall, Vancouver, BC V6T 1Z4. Email: renira.vellos@gmail.com 
International Journal of Child, Youth and Family Studies (2016) 7(2): 307-323

DOI: $10.18357 /$ ijcyfs 72201615723

Alternative education has existed for as long as public education, although it is sometimes considered evidence of the failure of individual children and youth or the failure of public schooling. When perceived as a "second chance" at schooling, there is often a stigma attached to the students who attend and the teachers who work with them (Vellos \& Vadeboncoeur, 2013). In addition, there is debate around the role of alternative schooling in contributing to the ongoing failure of the public school system to respond adequately to the needs of students. One view holds that alternatives allow public schools to push out students who are deemed "different" so that public schooling does not need to change to meet the needs of all students (Kelly, 1993). While there is little doubt that alternative schools may be "spaces of difference” (Vadeboncoeur, 2009, p. 284) and that, together, students and teachers in alternative schools may form “communities of difference” (Vellos, 2009, p. 116), our research suggests that a central characteristic of alternative education - offering second or additional chances - may be important for public schooling as a whole, rather than something that should be perceived as a weakness of alternative education.

Research across mainstream and alternative education is unequivocal in highlighting the significant role of student-teacher relationships: supportive relationships between students and teachers are central to learning, teaching, and education (de Jong, 2005; Lind, 2013; O’Connor \& McCartney, 2007). However, much research tends to focus on students as individuals, and measure attributes of individual students, rather than the qualities of the relationship between students and teachers. In our research, we have found that the principle of accept and build helps us to go beyond the label of "supportive," to better understand what may be a central quality of the relationships between students and teachers. The dialectical principle of accept and build highlights the role of the relationship between student and teacher in creating the dialectical space through which student and teacher work toward accepting what each has to offer in the present, while together building new social futures. Our perspective rests on an idea common to two different kinds of relationships: those between infants and caregivers as a dialectic of accept/build (Vygotsky, 1934/1987), and those between participants in improvisation as a dialectic of “yes/and” (Perone, 2011; Sawyer, 1997). In this article, we use the language of accept and build because it describes clearly a central quality in relationships between students and teachers that is significant for enabling students to overcome difficult educational histories and to re-engage in schooling.

Accept and build relies on the imagination, and specifically, what we are calling the moral imagination, based on the scholarship of Lev Vygotsky (1933/1967, 1934/1987, 1926/2004) and Maxine Greene (2000, 2008). Both students and teachers must engage in the joint imagining of new relationships, relationships that allow them to participate in the world in new and different ways. Here, the moral imagination refers to the dynamic learning, unlearning, and transforming of how we create social relationships with others, how we see ourselves in relationships, how we value our relatedness with others, and how we make decisions regarding 
International Journal of Child, Youth and Family Studies (2016) 7(2): 307-323

DOI: $10.18357 /$ ijcyfs 72201615723

what it means to become a supportive or empathetic person in relation. Imagining and creating relationships is an ongoing project of moral imagining across the life-course (Vadeboncoeur, Perone, \& Panina-Beard, 2016). As relationships evolve through joint imagining, new social futures for students and teachers are created and recreated.

Integrating qualitative data from research conducted in both Australia and Canada, we describe this particular quality of student-teacher relationships - the dialectical principle of accept and build — as a project of moral imagining. This article is divided into three sections. We begin by briefly reviewing the literature on student-teacher relationships both generally and in alternative schools and flexible learning centres. Second, drawing on the notion of moral imagining, we describe our own research, in both Australia and Canada, regarding the qualities of student-teacher relationships, and identify three themes to exemplify the principle of accept and build. Third, a discussion concludes this article emphasising that learning and teaching form a joint project of moral imagining for students and teachers across all school settings; one that may be more urgently felt in alternative education.

\section{Research on Student-Teacher Relationships}

The significant role of student-teacher relationships is found consistently across mainstream and alternative education contexts, as well as across various forms of research methodologies. Key characteristics of student-teacher relationships that make possible supportive learning and teaching experiences include connectedness, relatedness, and engagement. These characteristics are typically studied through surveys and self-reports completed by individual students, which are then generalised to the student population and often applied to the school context, rather than through studies of the relationships between students and teachers (Vadeboncoeur \& Rahal, 2013). Student-teacher relationships have also been found to shape engagement in social practices, such as attendance practices, and academic outcomes. In addition, early experiences for children in supportive relationships with teachers have mediating effects for future schooling and these effects are evident longitudinally. In this section, we provide a brief review of this literature.

The importance of supportive relationships with teachers is found in the literature across mainstream and alternative schools. In an analysis of the relationships between early school leaving, academic organisation, and social organisation in 190 high schools in the United States, Lee and Burkam (2003) found that "students stay in school when social relations with their teachers are positive” (p. 386). This finding held even when other factors were taken into account, including the background of students and demographic composition of the school. An interesting related finding was that the potential to have student-teacher relationships was reduced when high schools were over 1,500 students in size, owing, in part, to the anonymity such settings tend to produce. Survey research in Australia across 52 schools — including State, Catholic, and Independent schools — was conducted by de Jong (2005) to generate best 
International Journal of Child, Youth and Family Studies (2016) 7(2): 307-323

DOI: $10.18357 /$ ijcyfs 72201615723

practices. Of seven principles for best practice, creating positive relationships with students was identified as critical for supporting students and helping them achieve learning outcomes. Further, de Jong (2005) argued, "teachers should make it their priority to develop positive relationships with their students," including taking a personal interest in the life of each student, reflecting on the difference between teachers "earning” and "deserving” respect, and using good communication (p. 358). Participatory action research conducted by Lind (2013) in one alternative high school in Canada found that "supportive healthy relationships within the school environment were one of the most important factors in student capacity-building” (p. 462).

The significant role of student-teacher relationships for learning and teaching emerges across research designs and methodologies, including longitudinal, quantitative, and qualitative research. The Québec Longitudinal Study of Child Development (QLSCD 1998-2010) monitored more than 2000 children born in 1997 or 1998. Children were monitored annually, from the age of 5 months through to 8 years, and biannually from 8 to 12 years of age. Data collection was conducted again in 2011 when children were in their first year of high school. Monitoring included a range of forms of data collection, including engaging each child in activities to assess development, and working with teachers to assess development and adjustment to the school context for each child. As such, this study was the first large scale survey of student-teacher relationships to consider the perspectives of both students and teachers. The long-term impact of student-teacher relationships for academic achievement was so strong that the authors suggested intervening with children and teachers in order to foster the development of a positive relationship from the beginning of school (Desrosiers, Japel, Singh, \& Tétreault, 2012).

The long-term effects of positive student-teacher relationships that begin in kindergarten, as well as the potential effects of these relationships to mediate future difficulties, has also been established (Curby, Rimm-Kaufman, \& Ponitz, 2009; Pianta \& Stuhlman, 2004). A quantitative study of teacher evaluation policies and student outcomes in the United States found that the student-teacher relationship protected against student drop out (Barile et al., 2012). Qualitative studies in the United States, Canada, and Australia have also provided evidence for the power of student-teacher relationships in mediating the difficulties of previous educational experiences and enabling students to re-engage in schooling (Lind, 2013; Vadeboncoeur, 2005, 2009; Vellos, 2009).

Along with being linked to improvements in attendance and engagement in alternative programs (Vellos \& Vadeboncoeur, 2015), and academic competence and performance more generally (Hughes, Gleason, \& Zhang, 2005; Wenglinsky, 2002), student-teacher relationships are linked with feelings of connectedness (Hendry \& Reid, 2000), and relatedness and engagement (Furrer \& Skinner, 2003). According to Whitlock (2007), connectedness — as sense of belonging to school and attachment to others - is the strongest protective factor against a number of health challenges and a key contributor to the development of resilience. In research with over 600 children in Grades 3 to 6, by Furrer and Skinner (2003), belonging was described 
International Journal of Child, Youth and Family Studies (2016) 7(2): 307-323

DOI: $10.18357 /$ ijcyfs 72201615723

as having "an energetic function, awakening enthusiasm, interest, and willingness to participate in academic activities” (p. 158), and relatedness was described as a "buffer against negative emotions, minimizing feelings of boredom, anxiety, pressure, or frustration” (p. 158). These authors suggested that "qualities such as warmth, caring, sensitivity, dedication of attention and time, and emotional availability may be important to the development of secure relationships with adults” (p. 160). Further, they emphasised the importance of recognising the interconnectedness of relations between different social partners - including parents, peers, and teachers - and approaching the development of relationships with this social network in mind.

Our review of the literature on student-teacher relationships establishes the important role that student-teacher relationships play in learning and teaching and also foregrounds two additional points that are less well established. First, the potential of student-teacher relationships derives, in part, from the attachment between student and teacher (Lynch \& Cicchetti, 1997; Neufeld \& Maté, 2005). From this perspective, relationships are bidirectional, thus, both participants in the relationship grow as a result of the relationship. There is little research, however, that attends to the ways in which teachers grow through their relationships with students and little research that documents the student-teacher dyad as a unit of analysis (Vadeboncoeur \& Rahal, 2013). Second, it is important to consider how particular studentteacher relationships change over time and through experience, as well as how these relationships may change to reflect differing developmental needs and interests, again for both student and teacher; in effect, to see relationships as changing over time and across contexts (Vadeboncoeur \& Murray, 2014). Conceptualising this relationship further - coupling the principle of accept and build with empirical data — is the topic of the next section.

\section{Accept and Build: The Moral Imagining of Relationships}

The principle of accept and build is grounded in a particular view of human learning and developing: one that recognises that learning and developing are dynamic, relational, and continue throughout life (Vygotsky, 1934/1987). Emerging from Vygotsky’s (1934/1987) theory, learning and developing are processes through which children, young people, and adults change over time; how we change over time is a jointly constructed process with significant social others that is mediated by speech and systems of meaning-making. From this perspective, both student and teacher change and develop in relation and over the course of their lives. In this section, we use empirical data from research in Australia and Canada to elaborate on the dialectical principle of accept and build in relation to moral imagining.

\section{Theoretical Grounding for the Principle of Accept and Build}

Two aspects of Vygotsky’s (1934/1987) work are particularly relevant as theoretical grounding for the principle of accept and build. First, Vygotsky emphasised the role of caregivers in imposing meaning on an infant's actions, well before they may have been intended as meaningful by the infant. Infants are born into social worlds and they rely upon caregivers to 
International Journal of Child, Youth and Family Studies (2016) 7(2): 307-323

DOI: $10.18357 /$ ijcyfs 72201615723

interpret their gaze, movements, actions, and sounds as indicative: as indicating a desire for an object or intent for an action, and as attempts at communicating these with caregivers. For example, he described the way caregivers engage with an infant's movements and accept them as meaningful by building on a movement in the direction of a toy with a response such as, "Oh, is it the ball you want? Here it is, here's the red ball, this must have been what you wanted.” Caregivers accept the movement of the infant as meaningful and offer an interpretation for the movement; then they build upon and respond as if the meaning was intended by the infant. Caregivers often shape their response to the responses offered by the infant. If the infant frowns at the ball presented, the caregiver builds another interpretation of meaning potential and another offer for the infant.

Second, Vygotsky was less interested in assessing what an individual, of any age, could do independently — their actual level of development — and more interested in considering what she or he could do as a result of instruction with another person - their potential level of development. He advanced the concept of the zone of proximal development and emphasised that educators should consider what becomes possible for the learner — whether an infant, a toddler, a young child, a school-age child, an adolescent, or an adult — as a result of joint interaction. More specifically, what becomes possible when the joint interaction engages the learner in his or her zone of proximal development. In each case, the relationship is the context for and creates the possibility for this engagement, rather than a synonym for the zone of proximal development. Vygotsky's theory places an emphasis on the significant role of parents and educators in the learning and developing of children and young people, and provides a rationale for how this relationship works. It is the ability of both participants to do two seemingly paradoxical actions at once: from the teacher's perspective, accepting and welcoming a young person for what she or he brings to a relationship in the present, while building toward futures that become possible as a result of their joint interaction; and from the student's perspective, a willingness to accept the teacher's offer, in spite of previous difficulties in school(s), while contributing, as well, to the building of social futures together.

The dialectic of accept and build has been foundational to the work of Lois Holzman (2009) with young people and adults in both after school and workplace contexts. She argued that improvisation can be seen as a conversational zone of proximal development. It is a space of accepting and building, because the improvisational scene and the act of improvising are created simultaneously. It entails socially shared thinking and feeling. In addition, the action in improvisation is both a meaning-making activity and an activity through which additional meanings are revealed and can, therefore, be reflected upon. Other scholars have coupled the notion of improvisation with the zone of proximal development in imaginary play in early childhood education (Sawyer, 1997) and with adult learners of English as an additional language (Perone, 2011). Perhaps one of the reasons why accept and build is so relevant to learning and education is because it honours all participants as they are in the present moment, while acknowledging that they are also in the process of becoming in multiple possible futures that 
International Journal of Child, Youth and Family Studies (2016) 7(2): 307-323

DOI: $10.18357 /$ ijcyfs72201615723

have yet to be created. For example, the three year old engaging in imaginary play with her sister may repurpose a ball and create a motorcycle to ride, thereby becoming a motorcycle rider (Vadeboncoeur, 2016), while the adult learner who builds from the imaginary scene and what their improvisation partner offers, practices using English to gain proficiency as an English speaker (Perone, 2011). When the principle of accept and build guides interactions, both participants in the relationship are recognised as developing and dynamic; both participants are recognised as contributing to the relationship in ways that can be accepted and built upon.

The principle of accept and build requires the imagination "to disclose a different state of things, to open the windows of consciousness to what might be, what ought to be" (Greene, 2008, p. 18). It is imagination that allows children in imaginative play to act as if an over turned chair is a motorcycle or as if a playmate on it is riding the motorcycle. It is imagination that allows young people and adults to engage in the same sort of imaginary and playful practice when they participate in improvisation and, indeed, in any kind of imagining or creating for the future. Indeed, and consistent with a Vygotskian (1933/1967, 1926/2004) perspective, the imaginary situation that propels play in childhood is an opportunity to practice the imagining and creating that, across the life course, will be used to repurpose objects and actions and create anew (Vadeboncoeur et al., 2016). In an academic context, planning the actions to study for an exam, thinking through how to write a paper, or imagining the next steps after high school is completed all require the imagination. In addition, however, it is moral imagining that is required for social relationships, that "allows for empathy, for a tuning in to another's feelings, for new beginnings in transactions with the world" (Greene, 2008, p. 18). When a student imagines whether a teacher can be trusted, when a teacher imagines the previous educational experiences that are described by a student and can empathize — indeed, when any two people begin to form a relationship - it is the moral imagination that enables that beginning and enables a young person to begin again after difficult experiences in school.

\section{Accept and Build: Three Themes from Research in Australia and Canada}

This section offers three themes from our research in a flexible learning centre in Australia and an alternative program in Canada based upon a re-analysis that inquired into how the principle of accept and build may help explain how re-engagement in schooling was mediated. Research in Australia was conducted with young people and educators over the course of three years at a flexible learning centre in Queensland (Vadeboncoeur, 2009). Data were generated through ongoing observations, audio-taped interviews, field notes, and informal conversations. In November 2004, when 60 students in total attended the flexible learning centre, 17 interviews were conducted with students. A series of interviews were conducted with educators, including teachers, youth workers, and the principal, between 2003 and 2005.

Research in Canada was conducted over a four-month period with young people and educators at an alternative program of 97 students in Grades 11 and 12, and drew upon observations, interviews, field notes, and informal conversations, as well as documents (Vellos, 2009). Audio- 
International Journal of Child, Youth and Family Studies (2016) 7(2): 307-323

DOI: $10.18357 /$ ijcyfs 72201615723

taped interviews with eight students, teachers, youth and family workers, and the lead teacher were analysed thematically (Braun \& Clarke, 2006).

From across these two studies, three themes illustrate student-teacher relationships: being seen; recognising the capacity to grow; and co-creating social futures. In what follows, the names for participants are pseudonyms, and the term "flexible program” is used for both the flexible learning centre and the alternative program, and line numbers from interview transcripts are noted.

Theme 1 - Being Seen: The students reported that consistently in mainstream settings they were "invisible" and they were not treated as individuals. A key difference between mainstream schooling and their flexible program was "being seen.” Indeed, the majority of the young people noted their feelings of relief after leaving mainstream schooling, and an additional sense of relief in finding the flexible program where they re-engaged. When asked about this feeling of relief and why they continued to attend the flexible program, a common overlapping refrain emerged across the student interviews that established this theme: they were "seen." Teachers were able to "see them as individuals" given the smaller class sizes and were able to respond to their different needs, strengths, and interests with time and encouragement.

Coming from a family who "moved around a lot," Robert said the flexible program was, "Just better teachers, smaller classes, get around helping ya a lot” (L26-27). Fred, who had been excluded from school and went to a second high school, stated, "I thought it'd be different, but there's just more kids and less teachers. It's just ... really there were just too many classes and kids to look after" (L13-15). At his flexible program, "there’s smaller classes” and the teachers "focus more on the kids" (L21-22). Ann stated that the flexible program: "makes you take more responsibility for yourself ... make your own choices ... the teachers help you out heaps more ... teachers concentrate on you as well as everybody else, instead of just concentrating on a couple of people” (L41-47). In mainstream school, Joseph reported, “you'd be lucky to get two minutes of the teacher's attention," but he did not take it personally because he saw it happening to other students (L7). He noted, it seemed "natural” in schools for just a few students to receive attention from teachers (L11). The teachers in the flexible program "understand you more” (L37) and “[t]hey trust you” (L64). This feeling of support and trust surfaced from Alice's interview as well; she characterised her flexible program as a "friendly environment," "not crowded," and “you don’t get teased” (L26, 40, 42). Further, unlike mainstream school, here "teachers have the time to help you, and they are interested in helping” (L54-55, 70). Michael said, "I was in a big classroom, needed more attention,” and “teachers couldn’t help me as much as I needed the help. But here they can ... smaller classrooms so a teacher can give all the kids the same amount of help” (L8-9, 11-12, 22).

Being seen was about being visible in a particular way, for example, as an individual with individual needs, strengths, and interests, as opposed to being one of a class of 30 or more students. In this sense, being seen was about seeing difference, which was also noted in 
International Journal of Child, Youth and Family Studies (2016) 7(2): 307-323

DOI: $10.18357 /$ ijcyfs 72201615723

interviews with students and teachers. Dee, a student, noted that teachers were able to see and “approach different kinds of students” (L362) and Donald, also a student, noted that an important quality of good teachers was their ability to help students who "learn in different ways" (L160). The language of seeing difference, indeed, of expecting to see difference, and of an interest in learning about each student's differences, surfaced in every interview with teachers across both flexible programs. Jim, a teacher, noted his commitment to gaining “a sense of each person” (L453) and his willingness to continue to learn from and about each student. Being seen is significant to the principle of accept and build; without being seen, and an overall acceptance of differences between students, students cannot be accepted with the experiences they bring to the program. Being seen, thus, is a requirement for acceptance, for acknowledging the present moment as a space to begin. The role of the imagination is "to awaken, to disclose the ordinarily unseen, unheard, and unexpected” (Greene, 1995, p. 28). Further, Greene (1995) argued, what "seems crucial is the noticing" (emphasis added, p. 74).

Theme 2 - Recognising Capacity to Grow: Both students and teachers spoke about themselves as dynamic and developing; they also saw this quality in each other. Students' descriptions of mainstream school experiences reflected the imposition of stasis: a label or category that was predictive of future interactions. Students noted, for example, experiences of being labelled or categorised in a particular way, experiences with stereotyping, experiences with a lack of expectations, and experiences with attendance and disciplinary policies that also constructed labels. Stasis was imposed when the label or stereotype continued to shape the interactions between student and teacher. The theme of mutual development emerged from students' reports about the teachers in the flexible programs offering "second chances" and being willing to change the environment as needed for students. It also emerged from teachers' reports about seeing the young people as having the "capacity to grow," as well as seeing themselves as developing in relation to students and in evolving relationships with students.

When asked why she left mainstream school, Ann replied simply, “I’ve never left school, I’ve continued schools into [the flexible program]” (L2-3). She had been enrolled in three mainstream schools before arriving at the flexible program. She said the program:

for me is a second chance ... they give you choices here ... instead of telling you what to do they ask you if you want to do it. They ask you to do your work, but obviously, you have to accept the consequences if you don't. (L32-38)

Roy stated that his teachers at the flexible program expected him "to learn" and worked with him as needed, rather than expecting him "to know" the material in advance (L31-32). Jenny, another student, noted that good teachers are "not gonna give up on you ... they'll always give you another chance ... You need as many chances as you need” to learn the material (L197-202). When Rebecca was asked what advice she would like to offer teachers and schools, she said, “To give people a second chance ... and not be too harsh on them if they do something that's bad ... 
International Journal of Child, Youth and Family Studies (2016) 7(2): 307-323

DOI: $10.18357 /$ ijcyfs 72201615723

and get to know them before you judge them” (L49-51). Several students noted that, once they had been labelled as a certain "kind of student," their teachers in mainstream schools stopped asking questions and inquiring into problems in school — from the location of assignments to fights with other students - and just imposed consequences without listening to "both sides." Barry, the principal of the flexible program, described this as a situation of "a pattern becoming more important than a person” (L271).

For Jim, a teacher, the definition of a "good teacher" included offering students understanding, and being fair and listening, as well as giving students "the benefit of the doubt ... the chance or the opportunity, the second chance if needed, to succeed” (L438-440). Connie, a teacher, intentionally used the language of change with her students, connecting with them about the aspects of their lives that they were happy with and those that they wanted to work on changing. She was careful to walk this path with them, noting her own concerns, difficulties, and moments of personal transformation over time and stated, "Even the tiniest change can be a symbol for our own potential to be different” (L76). She paid attention when students mentioned that they "couldn't do" certain subjects like maths or grammar. Her response was to enquire if this was still the case and to remark, "How do you know? What have you tried since that last experience with maths? Why don't you have a go with me and we'll see if things are different now?” (L81-91). She highlighted the importance of helping students "not believe the things they've been told about themselves" (L79), in effect, unlearning what they had learned, as well as coming to see themselves as "having the capacity to grow" (L92).

An outreach worker, Francie, reported that all the young people that she worked with were different: they had different educational and experiential histories, strengths, needs, interests, worries, and concerns. However, what unified her approach to working with young people was to begin by attending to all of these differences through "building relationships." Francie stated that relationships were not achieved "once and for all," but that "the very strong and powerful effect" of relationships needed to be tended to in an ongoing way (L149). When "young people have been let down a lot in the past" - including bad experiences in schools and bad experiences with adults, most of whom were teachers - a young person's response to educators, to adults, seemed warranted given their experiences (L151). Her goal was to build relationships and trust and "make sure we deliver on what we say we can help young people with, including accessing this learning environment and ... changing the environment if needed and supporting them as they work toward their goals” (L153-155). Further, she noted a particular vantage point from which educators viewed students:

We see their strengths, strengths that they sometimes don't even see, and inspire them, they've got so much to offer to each other and to us, they need to know we see the benefits of what they can offer together with continuing to learn and grow. (L165) 
International Journal of Child, Youth and Family Studies (2016) 7(2): 307-323

DOI: $10.18357 /$ ijcyfs 72201615723

Greene (2000a) argued that there is "something vitally important to education in the idea that the consciousness of growing, becoming different, can be tied to some memory of feelings of wonder, of recognition, that can counteract the feelings of futility" associated with schooling (p. 273). Along with Connie's acknowledgement of the importance of sharing her own development in discussions with students, and Francine's recognition that sometimes teachers need to change the school environment to enable students' access, another teacher, Jim, also described his own process of learning and being "willing to improve, and look at other alternative ways of teaching to make sure that the student succeeds" (L456-457). Recognising that both students and teachers change in relation to each other enabled both to begin the process of building something new. From this perspective, the flexible programs would be "different places" from mainstream schools and these teachers would be different from the teachers with whom students had had difficult experiences. The students were able to, in a sense, move beyond their previous histories to see potential abilities that had not been seen and futures that were not possible before. Most significantly, their engagement was mediated and they were enabled to, in Connie’s words, “have a go” (L84).

Theme 3 - Co-Creating Social Futures: Throughout the interviews, students and teachers referred to the ways in which their relationships enabled students to learn academic material and life lessons, to access learning opportunities outside the program, and to stabilise their accommodation, employment, and schooling experiences, as well as to remediate relationships with family and community. Teachers most often mentioned learning from the students in ways that resulted in "seeing the material differently", or learning about "the fragmentation of services" that young people experienced in order to help them navigate the systems. Students most often commented about learning to think about themselves differently and gaining access to learning and employment experiences. For both students and teachers, each idea mentioned affected the range of social futures that were being co-created. For example, as teachers came to see the material in different ways they co-created additional learning opportunities as options for students for further study.

Teachers contributed to the mediation of student re-engagement in flexible programs making possible new social futures. A student, Joan, recounted the story of her mother receiving a phone call from "the school" telling her that Joan had failed so many courses that she was not welcome to return to school. She said, they told her mother, "I was a failure" and I believed them for three and a half years (L6-7). While she was relieved upon leaving the school, "[i]n another way I was sad because I missed out on a lot of schooling ... not schooling, really, I was always there, but I was in what they called the 'planning room' ... so I missed ... a lot of class” (L1923). Segregated from her classmates, without support for her learning differences, Joan had learned from school that she couldn't learn. When her mother located the flexible program, and enrolled her, Joan discovered the program was different: "like the teachers give you a chance and they believe in you. They listen to what you have to say” (L39-40). Further: 
International Journal of Child, Youth and Family Studies (2016) 7(2): 307-323

DOI: $10.18357 /$ ijcyfs 72201615723

[t]hey take the time to understand ... My teachers care. You can do this, or this, or this ... they don’t go too fast and then test you and then you get stuff wrong cause you were rushed. ... You have the time and help to really learn, then you can learn. (L51-70)

Her experiences at the flexible program enabled Joan to learn that she was capable of learning, a quality Holzman (2009) called "that-ness” (p. 83). As a learner, new social futures became possible. For Joseph, as well, new social futures became possible because teachers "find out what you want to do and then help you get there ... not just getting stuff done, but finding out more about you and then making good suggestions” (L37-44).

David, an outreach worker, described his concern with the fragmentation of services created for young people and the difficulty of navigating them. Some of the young people he worked with needed accommodation, employment, and education all at the same time. He noted that the majority of young people he worked with were "smart academically, socially, emotionally, and they can look after themselves physically” (L165-166). What they did not have was access to stable accommodation and employment, and without access to this stability, they often lost access to the system of schooling and the credentials that it offered. When he was able to mediate their navigation of these systems to access accommodation and employment, the influence on the young person's life was astounding: attention to learning and education fell "into place" (L45). For David, participating in this process and "the relationships and the rapport that you build with young people are absolutely life-changing” for participants - educators as well as students (L254-255).

A principal, Barry, noted that for some of the students, their needs were created from "first and foremost a sense of neglect, a sense of alienation, and in some of the cases I know, this makes sense with their experiences, and there's a sense of despair about education” (L365-367). This despair, he argued, led to a cycle that was three-fold: feeling that school was too hard; "bumping up against authority figures;" and "constantly being pushed away from the group," for example, being sent out of class, or expelled from school (L369-370). Along with isolation and anger, what young people were learning from school was:

I'm not worthy, I'm not wanted, and you're outside the group. They're learning that they lack an understanding of this particular community, school, ... for some kids, there are deeper concerns about disabilities and these have implications in terms of your ability to fit in the mainstream, and to participate at the level you seem to be required to participate, at the pace, the speed. (L373-377)

Barry noted that the cycle may begin with a difficult experience, with a sense of isolation, with a feeling of difference, and then once it begins it continues with more isolation and less learning and teaching. He noted that he could see this cycle unfold and had a sense of the limited futures that were being created long before students disengaged. The question about which he was most concerned was how to break this cycle. 
International Journal of Child, Youth and Family Studies (2016) 7(2): 307-323

DOI: $10.18357 /$ ijcyfs 72201615723

At the time of these interviews, the flexible program was trying to break this cycle by building a sense of community in the present, along with mediating access to other communities, including back to mainstream school, to Technical and Further Education Programs (TAFE), and even to the cultural communities of the young people. Barry emphasised that, "none of this works if the curriculum is the driving focus. It only works in this setting, if it's relational, so ... the authenticity of the relationship is paramount for any kind of educational learning to happen" (L496-500). Mediating access to educational experiences was one role the alternative program played. A second role was mediating relationships with cultural communities, including creating ways for young people to begin "relationship[s] with elders in the community, both Indigenous and non-Indigenous ... with, you could say, esteemed adults, and reconnect youth to appropriate and relevant role models” (L493-495). For Barry, this work was necessary to counter the effects of a fragmented and fragmenting system of services, a system that was undergoing so much change itself that by the time young people sorted out how to navigate it, funding requirements, programs, and the services provided had often changed.

One teacher, Jim, made a similar argument: that part of the purpose of his relationships with students was imagining with them a sense of community, and sharing with his students the sense that "you belong to this community." (L271-272). Part of the process of building community was responding to students' strengths and interests and exploring different learning opportunities and teaching methods to engage each student. Linda, a lead teacher, noted two important pieces of advice about teaching in alternative settings. First, the curriculum does not exist as something separate from the learner: the curriculum must be created in relation to the learner and the experiences of the learner. From this perspective, the curriculum has to be built with the students and this collaborative work is part of the process of building community. The creation of communities in classrooms and schools, though perhaps "one of the most difficult and yet most essential undertakings in the schools," may be a method and an outcome of reaching beyond the concrete lived experiences of students and teachers toward a future that is in the process of becoming (Greene, 2000a, p. 273). Second, she noted that the responsiveness and supportiveness of teachers in flexible programs is a quality that is "really relevant to all teaching” and that this approach likely offers "preventative measures” worthwhile to consider across schools (L128-129). From Linda's experience, mainstream education had something to learn from the kind of student-teacher relationships that were created in the flexible program where she worked.

Both students and educators emphasised what becomes possible over time as relationships between students and teachers are beginning, building, and becoming more established. The interviews with the students and educators of the flexible programs illustrate the usefulness of examining student-teacher relationships through the principle of accept and build. First, students experienced being seen by teachers who also acknowledged and expected their different needs and interests. Second, both students and teachers recognized the capacity to grow 
International Journal of Child, Youth and Family Studies (2016) 7(2): 307-323

DOI: $10.18357 /$ ijcyfs 72201615723

in themselves and each other. Third, students and teachers worked together to create social futures that were enlarged to include new educational opportunities and connections to culture and community. These relationships became possible for both students and teachers as a result of their moral imaginings: It is imagination that "above all, makes empathy possible. It allows us to break with the taken for granted, to set aside familiar distinctions and definitions” (Greene, 1995, p. 3). Moral imagination allows teachers to accept their students in the present, while knowing them as developing entities, and imagining with them social futures that become possible as a function of evolving teacher-student relationships. The moral imagination also enables teachers to see themselves as transformed by their relationships with students, as learners and educators simultaneously, and as capable of creating futures with students that are more equitable (Vadeboncoeur et al., 2016).

\section{Concluding Thoughts}

What emerges across these flexible learning sites is the attention paid by the participants — both students and teachers - to social relationships, their interest in learning how to relate to each other dynamically and openly, and in so doing, to transform how they engage in schooling. This process is transformative in a number of ways: it allows students and teachers in relation to reflect on and consider what they value in each other and themselves, to consider how they see themselves and who they are becoming and, ultimately, to recreate social futures together. We argue here that what enables relationships based on the principle of accept and build is the moral imagination. It is the moral imagination that enables students to accept, yet again, what teachers have to offer and begin re-engaging with schooling. It is the moral imagination that enables teachers to welcome, respect, and accept each student as she or he is in the present moment, while also seeing beyond what is evident to what becomes possible as a result of their relationship. This sort of relationship is the foundation of educational experiences.

Education must guide children toward the development of imagination and creativity to make possible "the inner spaces that imagination can open up when it discloses untapped possibilities ... alternative realities or ways of being” (Greene, 2000a, p. 8). When this occurs, she maintained that:

individuals are far more likely to break with the ordinary and the taken-for-granted. Visions may appear before their mind's eye — visions of what might be, what ought to be. Experiences of this kind are what direct attention to the deficiencies, the inequities in lived situations; they may, in fact, provoke persons to take action together - to transcend the deficiencies, to transform. (pp. 8-9)

From this perspective, the deficiencies noted are not located in the children or the young people with whom we work, but rather in the social institutions we have created, the fragmentation among the services that we provide for them, and our approaches to schooling. This idea provides a reason for why we must grow alongside our students: although we can see 
International Journal of Child, Youth and Family Studies (2016) 7(2): 307-323

DOI: $10.18357 /$ ijcyfs72201615723

deficiencies in what has been created, we nonetheless struggle to think outside of these systems. Imagining and creating a system of schooling that is more in line with what education could be relies on our commitment to reimagining schooled practices, such as student-teacher relationships, with young people as our guides. It also relies on working together to take action to transform these practices, as well as the institutions within which they occur. 
International Journal of Child, Youth and Family Studies (2016) 7(2): 307-323

DOI: $10.18357 /$ ijcyfs 72201615723

\section{References}

Barile, J. P., Donohue, D. K., Anthony, E. R., Naker, A. M., Weaver, S. R., \& Henrich, C. C. (2012). Teacher-student relationship climate and school outcomes: Implications for educational policy initiatives. Journal of Youth and Adolescence, 41(3), 256-267. doi:10.1007/s10964-011-9652-8

Braun, V., \& Clarke, V. (2006). Using thematic analysis in psychology. Qualitative Research in Psychology, 3(2), 77-101. doi:10.1191/1478088706qp063oa

Curby, T. W., Rimm-Kaufman, S. E., \& Ponitz, C. C. (2009). Teacher-child interactions and children's achievement trajectories across kindergarten and first grade. Journal of Educational Psychology, 101(4), 4, 912-925. doi:10.1037/a0016647

de Jong, T. (2005). A framework of principles and best practice for managing student behaviour in the Australian education context. School Psychology International, 26(3), 353-370. doi:10.1177/0143034305055979

Desrosiers, H., Japel, C., Singh, P. R. P., \& Tétreault, K. (2012). Positive teacher-student relationships: Associations with child characteristics and academic achievement in elementary school. Québec Longitudinal Study of Child Development (QLSCD 1998-2010): From Birth to 10 Years of Age (Vol. 6, Fascicle 2). Québec, PQ: Institut de la statistique du Québec. Retrieved from

http://www.jesuisjeserai.stat.gouv.qc.ca/pdf/publications/feuillet/ELDEQ_fasc6no2_an.pdf

Furrer, C., \& Skinner, E. (2003). Sense of relatedness as a factor in children's academic engagement and performance. Journal of Educational Psychology, 95, 148-162. doi:10.1037/0022-0663.95.1.148

Greene, M. (1995). Releasing the imagination: Essays on education, the arts and social change. San Francisco, CA: Jossey-Bass.

Greene, M. (2000a). Imagining futures: The public school and possibility. Journal of Curriculum Studies, 32(2), 267-280. doi:10.1080/002202700182754

Greene, M. (2000b). The ambiguities of freedom. English Education, 33(1), 8-14.

Greene, M. (2008). Education and the arts: The windows of imagination. Learning Landscapes, 1(3), 17-21.

Hendry, L. B., \& Reid, M. (2000). Social relationships and health: The meaning of social “connectedness" and how it relates to health concerns for rural Scottish adolescents. Journal of Adolescence, 23(6), 705-719. doi:10.1006/jado.2000.0354

Holzman, L. (2009). Vygotsky at work and play. New York, NY: Routledge. 
International Journal of Child, Youth and Family Studies (2016) 7(2): 307-323

DOI: $10.18357 /$ ijcyfs 72201615723

Hughes, J. N., Gleason, K. A., \& Zhang, D. (2005). Relationship influences on teachers’ perceptions of academic competence in academically at-risk minority and majority first grade students. Journal of School Psychology, 43(4), 303-320.

doi:10.1016/j.jsp.2005.07.001

Kelly, D. M. (1993). Last Chance High: How girls and boys drop in and out of alternative schools. New Haven, CT: Yale University Press.

Lee, V. E., \& Burkam, D. T. (2003). Dropping out of high school: The role of school organization and structure. American Educational Research Journal, 40(2), 353-393.

Lind, C. (2013). What builds capacity in an alternative high school setting? Educational Action Research, 21(4), 448-467. doi:10.1080/09650792.2013.847717

Lynch, M., \& Cicchetti, D. (1997). Children's relationships with adults and peers: An examination of elementary and junior high school students. Journal of School Psychology, 35(1), 81-99.

Neufeld, G., \& Maté, G. (2005). Hold on to your kids: Why parents need to matter more than peers. Toronto, ON: Vintage Canada.

O'Connor, E., \& McCartney, K. (2007). Examining teacher-child relationships and achievement as part of an ecological model of development. American Educational Research Journal, 44(2), 340-369. doi:10.3102/0002831207302172

Perone, A. (2011). Improvising with adult English language learners. In R. K. Sawyer (Ed.), Structure and improvisation in creative teaching (pp. 162-183). Cambridge, UK: Cambridge University Press.

Pianta, R. C., \& Stuhlman, M. W. (2004). Teacher-child relationships and children's success in the first years of school. School Psychology Review, 33, 444-458.

Sawyer, R. K. (1997). Pretend play as improvisation: Conversation in the preschool classroom. Mahwah, NJ: Lawrence Erlbaum.

Vadeboncoeur, J. A. (2005). The difference that time and space make: An analysis of institutional and narrative landscapes. In J. A. Vadeboncoeur \& L. P. Stevens (Eds.), Re/constructing "the adolescent”: Sign, symbol and body (pp. 123-152). New York, NY: Peter Lang.

Vadeboncoeur, J. A. (2009). Spaces of difference: The contradictions of alternative educational programs. Educational Studies, 45(3), 280-299. doi:10.1080/00131940902910974

Vadeboncoeur, J. A. (2016). Vygotsky for educators: A unity of theory and practice. New York, NY: Peter Lang. 
International Journal of Child, Youth and Family Studies (2016) 7(2): 307-323

DOI: $10.18357 /$ ijcyfs 72201615723

Vadeboncoeur, J. A., \& Murray, D. (2014). Imagined futures in the present: Minding learning opportunities. National Society for the Study of Education, 113(2), 633-652.

Vadeboncoeur, J. A., Perone, A., \& Panina-Beard, N. (2016). Creativity as a practice of freedom: Imaginative play, moral imagination, and the production of culture. In V. P. Glaveanu (Ed.), Palgrave Studies in Creativity and Culture: The Palgrave handbook of creativity and culture research (pp. not available). London, UK: Palgrave Macmillian.

Vadeboncoeur, J. A. \& Rahal, L. (2013). Mapping the social across lived experiences: Relational geographies and after-school time. Banks Street Occasional Paper Series, 30, 1-15.

Vellos, R. E. (2009). Re-engagement in learning contexts: Negotiations between adults and youth sin the zone of proximal development (Unpublished master's thesis). The University of British Columbia, Vancouver, BC.

Vellos, R. E., \& Vadeboncoeur, J. A. (2013). Alternative and second chance education. In J. Ainsworth \& J. G. Golson (Eds.), Sociology of Education (pp. 35-39). Thousand Oaks, CA: Sage Reference.

Vellos, R. E., \& Vadeboncoeur, J. A. (2015). Rebuilding attendance practices with youth: The role of social mediation. Educational Studies, 41(1-2), 91-108. doi:10.1080/03055698.2014.955735

Vygotsky, L. S. (1926/2004). Imagination and creativity in childhood. Journal of Russian and East European Psychology, 42(1), 7-97.

Vygotsky, L. S. (1933/1967). Play and its role in the mental development of the child. Soviet Psychology, 5(3), 6-18.

Vygotsky, L. S. (1934/1987). Thinking and speech. In R. W. Rieber \& A. S. Carton (Eds.), The collected works of L. S. Vygotsky: Volume 1 (pp. ix-285). New York, NY: Plenum.

Wenglinsky, H. (2002). How schools matter: The link between teacher classroom practices and student academic performance. Educational Policy Analysis Archives, 10(12), 1-30. Retrieved from http://epaa.asu.edu/ojs/article/view/291/417

Whitlock, J. (2007). The role of adults, public space, and power in adolescent community connectedness. Journal of Community Psychology, 35(4), 499-518. doi:10.1002/jcop.20161 